\title{
CXVIII. STUDIES IN THE BIOCHEMISTRY OF MICRO-ORGANISMS.
}

\author{
XXXVIII. THE METABOLIC PRODUCTS \\ OF PENICILLIUM MINIO-LUTEUM \\ DIERCKX. MINIOLUTEIC ACID.
}

\author{
BY JOHN HOWARD BIRKINSHAW AND HAROLD RAISTRICK. \\ From the Division of Biochemistry, London School of Hygiene and \\ Tropical Medicine, University of London.
}

(Received April 25th, 1934.)

Penicillium minjo-Luteum Dierckx was described by R. P. Dierckx [1901] and is referred to by Biourge [1923, p. 237] and by Thom [1930, p. 464] in their monographs on the genus Penicillium. We have found that when this organism is grown at $24^{\circ}$ on Czapek-Dox medium containing glucose as the sole source of carbon a highly pigmented metabolism solution is formed which froths very badly on vacuum-evaporation. The metabolism solution gives heavy amorphous precipitates with aqueous solutions of the salts of many heavy metals, e.g. barium, calcium, copper, nickel, lead, iron, and with silver on standing, but gives no precipitate with mercuric salts. Further, on strongly acidifying the metabolism solution a somewhat pigmented crystalline precipitate is formed on standing. Investigation of the barium and copper precipitates and also of the crystalline precipitate formed on acidification has led to the isolation of two colourless crystalline acids : (1) The $\gamma$-lactone of $\gamma$-hydroxy- $\beta \delta$-dicarboxypentadecanoic acid, $\mathrm{C}_{17} \mathrm{H}_{28} \mathrm{O}_{6}(\mathrm{I})$. This acid was previously described by Clutterbuck et al. [1931] as a metabolic product of $P$. spiculisporum Lehman, and is now for convenience given the name spiculisporic acid. (2) A hitherto undescribed, dextrorotatory acid having the empirical formula $\mathrm{C}_{16} \mathrm{H}_{26} \mathrm{O}_{7}$, for which the name minioluteic acid is proposed. It is interesting to note that Thom [1930] places $P$. spiculisporum Lehman and $P$. minio-luteum Dierckx in the Biverticillata-Symmetrica group of species of Penicillium on morphological grounds.

Minioluteic acid titrates in the cold as a dibasic acid, but a third acidic group is unmasked by heating with an excess of aqueous alkali. Since the third carboxyl group is masked again on acidification, minioluteic acid is obviously a lactonic acid. This view is supported by the fact that minioluteic acid gives a dimethyl ester and a trihydrazide. Since minioluteic acid contains no unsaturated linkages, and apart from the lactone ring must, from its empirical formula, be an open chain compound, it is obviously the monolactone of a dihydroxytricarboxylic acid.

On fusion with potash, oxalic acid, $n$-dodecanoic acid and a dibasic acid having the empirical formula $\mathrm{C}_{14} \mathrm{H}_{26} \mathrm{O}_{4}$ were obtained. This acid was proved by synthesis to be decylsuccinic acid (II).

On reduction with sodium amalgam, minioluteic acid gives the lactone of a dicarboxylic acid, $\mathrm{C}_{15} \mathrm{H}_{28} \mathrm{O}_{4}$, which has been shown by synthesis to be the $\gamma$-lactone of $\alpha$-hydroxy- $\gamma$-carboxy- $n$-tetradecanoic acid (III). 
On the basis of these facts it appears that minioluteic acid is the $\gamma$-lactone of $\alpha \beta$-dihydroxy- $\beta \gamma$-dicarboxy-n-tetradecanoic acid (IV).

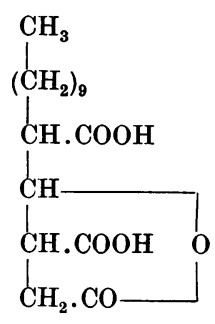

I

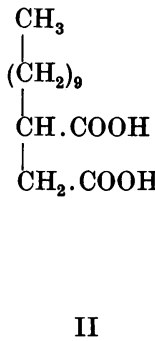

II

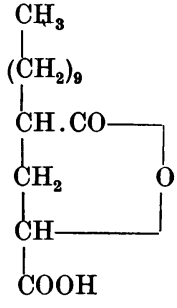

III

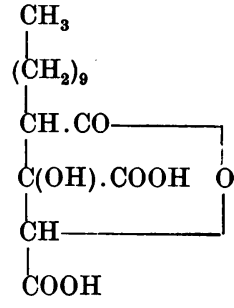

IV

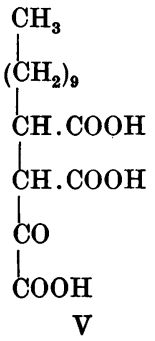

\section{EXPerimental.}

Organism.

The organism used in the whole of this work was a culture of $P$. minio-luteum Dierckx (London School of Hygiene and Tropical Medicine Catalogue No. P 44), received originally through the courtesy of Prof. P. Biourge of the University of Louvain in December 1929. It bears Prof. Biourge's Catalogue No. 60, and is actually a subculture of the original organism isolated by Dierckx.

\section{Culture medium and course of metabolism.}

The medium used was the ordinary Czapek-Dox solution of the following composition: glucose, 50 g.; $\mathrm{NaNO}_{3}, 2 \mathrm{~g}$.; $\mathrm{KH}_{2} \mathrm{PO}_{4}, 1 \mathrm{~g}$.; $\mathrm{KCl}, 0.5 \mathrm{~g}$.; $\mathrm{MgSO}_{4}$, $7 \mathrm{H}_{2} \mathrm{O}, 0.5 \mathrm{~g}$.; $\mathrm{FeSO}_{4}, 7 \mathrm{H}_{2} \mathrm{O}, 0.01 \mathrm{~g}$.; water to $1000 \mathrm{ml}$.

Since preliminary experiments showed that better growth and quicker metabolism were obtained at $24^{\circ}$ than at $30^{\circ}$ the former was used throughout as the temperature of incubation. Batches of 100 one-litre conical flasks, each containing $350 \mathrm{ml}$. of the above Czapek-Dox solution, were sterilised and sown with a spore suspension of $P$. minio-luteum and incubated at $24^{\circ}$. Growth was fairly rapid at first and produced a whitish mycelium with green areas of conidial growth. As growth proceeded the mycelium became predominantly green with pinkish patches. The metabolism solution, which quickly developed a faint purple colour, gradually became darker in colour until after 5 weeks it was very dark brown. At the end of the incubation period the contents of the flasks in each batch were filtered and treated by one or other of the following methods:

Method $A$. This method depends on the fact that both minioluteic and spiculisporic acids are precipitated from aqueous solution by various metallic salts. The filtered metabolism solution and washings, having $p_{\mathrm{H}} 4 \cdot 2-4 \cdot 3$, were treated with a $40 \%$ aqueous solution of barium acetate (128 g.). The precipitate was filtered off and to the filtrate, which now had $p_{\mathrm{H}} 5 \cdot 2,100 \mathrm{~g}$. of copper acetate dissolved in about 1 litre of hot water were added. The filtrate from the copper precipitate, having $p_{\mathrm{H}} 5 \cdot 0$, was treated with a slight excess of aqueous normal lead acetate solution, and the filtrate from this precipitate was brought to $p_{\mathrm{H}} 6.2$ by the addition of $450 \mathrm{ml} .2 \mathrm{~N} \mathrm{NaOH}$ and precipitated with basic lead acetate solution. The acids contained in the various precipitates were now extracted as follows:

1. Barium precipitate. The barium precipitate was ground with an excess of an aqueous solution of sodium sulphate at $60^{\circ}$ and filtered hot; the filtrate was acidified with a slight excess of $2 \mathrm{~N} \mathrm{H}_{2} \mathrm{SO}_{4}$ and extracted twice with rather less than its own volume of ether. On evaporation of the ether a semicrystalline 
solid, weight $46 \cdot 1 \mathrm{~g}$., remained. On fractional crystallisation from water and decoloration with norite a less soluble fraction, weight $17 \cdot 3 \mathrm{~g}$., of almost pure minioluteic acid, melting at $170^{\circ}$ was obtained. The more soluble fraction was fractionated from a mixture of ether and light petroleum giving $3.7 \mathrm{~g}$. of somewhat impure spiculisporic acid, which on further purification melted at $142-144^{\circ}$. This was identified by comparison with an authentic specimen of spiculisporic acid from $P$. spiculisporum.

2. Copper precipitate. The copper precipitate was ground with water, treated with $150 \mathrm{ml} .5 \mathrm{~N} \mathrm{HCl}$ in which practically the whole dissolved, and extracted with ether. The ether extract on evaporation gave $37.9 \mathrm{~g}$. of a dark-coloured semicrystalline mass, from which by fractionation from hot water $17.7 \mathrm{~g}$. of crystalline material were obtained. Nothing but spiculisporic acid (M.P.144-145.5 could be isolated from this fraction. No minioluteic acid could be isolated from the copper precipitate.

3. Lead precipitates. The normal lead and basic lead precipitates were separately ground with excess of dilute sulphuric acid and filtered from the precipitated lead sulphate, and the filtrate was extracted with ether. The ether extract from the normal lead acetate precipitate proved to be an uncrystallisable syrup from which nothing was isolated. The ether extract from the basic lead acetate precipitate consisted essentially of an uncrystallisable syrup. A small amount ( $0.6 \mathrm{~g}$.) of a complex mixture of colourless crystalline substances was however isolated, but this has not been further investigated.

Method $B$. The combined filtered metabolism solution and washings from one batch of 100 flasks were acidified with 3 litres of concentrated $\mathrm{HCl}$ and left in the cold room overnight. The precipitated pigmented, crystalline material was filtered off, washed, dried and weighed ( $80.5 \mathrm{~g}$.). It consisted of a mixture of minioluteic, spiculisporic and possibly other acids, which up to the present have not been isolated in a state of purity. The crude pigmented crystalline mixture was recrystallised six times from hot water (norite), giving $40 \mathrm{~g}$. of colourless material, M.P. $150-156^{\circ}$. Minioluteic acid was separated from this material by taking advantage of the fact that, in contrast with spiculisporic acid, it forms a potassium salt which is insoluble in ethyl alcohol. $40 \mathrm{~g}$. were dissolved in 1 litre of ethyl alcohol, and a solution containing $24 \mathrm{~g}$. of anhydrous potassium acetate in $500 \mathrm{ml}$. of ethyl alcohol was added slowly and with constant shaking. The precipitated potassium salt was filtered off after half an hour, washed with ethyl alcohol, dissolved in about $900 \mathrm{ml}$. of warm water and treated with $90 \mathrm{ml}$. of concentrated $\mathrm{HCl}$. After cooling, the acid was filtered off and dried; yield 34 g., M.P. $164-167^{\circ}$. The alcoholic mother-liquors were evaporated

\begin{tabular}{|c|c|c|c|c|c|c|}
\hline $\begin{array}{l}\text { Exp. } \\
\text { No. }\end{array}$ & $\begin{array}{l}\text { Incubation } \\
\text { period in } \\
\text { days }\end{array}$ & $\begin{array}{l}\text { Apparent } \\
\text { residual } \\
\text { glucose by } \\
\text { polarimeter } \\
\quad \%\end{array}$ & $\begin{array}{c}\text { Final } \\
p_{\mathrm{H}}\end{array}$ & $\begin{array}{l}\text { Method of } \\
\text { isolation }\end{array}$ & \multicolumn{2}{|l|}{$\begin{array}{l}\text { Yields of crude products } \\
\text { g. }\end{array}$} \\
\hline 1 & 47 & $0 \cdot 23$ & $4 \cdot 3$ & $\mathbf{A}$ & $\begin{array}{l}E x \text { Ba precipitate } \\
E x \text { Cu precipitate } \\
E x \text { basic } \mathrm{Pb} \text { precipitate }\end{array}$ & $\begin{array}{r}46 \cdot 1 \\
37 \cdot 9 \\
9 \cdot 0\end{array}$ \\
\hline 2 & 52 & $0 \cdot 11$ & $4 \cdot 2$ & A & $\begin{array}{l}E x \text { Ba precipitate } \\
E x \text { Cu precipitate } \\
E x \text { normal } \mathrm{Pb} \text { precipitate } \\
E x \text { basic } \mathrm{Pb} \text { precipitate }\end{array}$ & $\begin{array}{r}52 \cdot 5 \\
37 \cdot 1 \\
4 \cdot 7 \\
13 \cdot 0\end{array}$ \\
\hline 3 & 50 & $0 \cdot 10$ & - & B & & 80.5 \\
\hline 4 & 53 & $0 \cdot 16$ & - & B & & $75 \cdot 5$ \\
\hline
\end{tabular}


in vacuo and dissolved in water, and the acid was precipitated by $\mathrm{HCl}$; yield $3 \cdot 3 \mathrm{~g}$., M.P. $134-137^{\circ}$. The main fraction melting at $164-167^{\circ}$ was now re-precipitated as the potassium salt which was further purified by crystallising once from water. By this means $18 \cdot 3 \mathrm{~g}$. of pure minioluteic acid melting at $171^{\circ}$ were isolated. Pure spiculisporic acid was obtained by fractional crystallisation of the material from the alcohol-soluble potassium salt.

The experimental details of each of four batches of 100 flasks each are given in Table I.

\section{General properties of minioluteic acid.}

Minioluteic acid is best purified by crystallisation from hot water from which solvent it separates in colourless needles melting at $171^{\circ}$. (Found by Schoeller: C, 58.00, 57.96; H, 7.65, 7.72\%; $\mathrm{OCH}_{3}$, nil; $\mathrm{N}$, nil; mol. wt., 317, 332. $\mathrm{C}_{16} \mathrm{H}_{26} \mathrm{O}_{7}$ requires: $\mathrm{C}, 58 \cdot 14 ; \mathrm{H}, 7 \cdot 93 \%$. Mol. wt., 330 .)

Titration. 0.1576 g. dried to constant weight at $105^{\circ}$ and dissolved in $10 \mathrm{ml}$. ethyl alcohol required $9.55 \mathrm{ml}$. $N / 10 \mathrm{NaOH}$ corresponding to an equivalent of $165\left(\mathrm{C}_{16} \mathrm{H}_{26} \mathrm{O}_{7}\right.$ titrating as a dibasic acid requires 165$)$. A further $20 \cdot 00 \mathrm{ml} . N / 10$ $\mathrm{NaOH}$ were now added, the mixture heated on the water-bath for 2 hours, cooled and back-titrated with $N / 10 \mathrm{HCl}$. A further $4.68 \mathrm{ml}$. $N / 10 \mathrm{NaOH}$ were neutralised during hydrolysis, making a total of $14.23 \mathrm{ml} . N / 10 \mathrm{NaOH}$ and corresponding with an equivalent of $110 \cdot 7\left(\mathrm{C}_{16} \mathrm{H}_{26} \mathrm{O}_{7}\right.$ titrating as a tribasic acid requires 110). Minioluteic acid thus titrates in the cold as a dibasic, and on heating as a tribasic acid. $14 \cdot 23 \mathrm{ml} . \mathrm{N} / 10 \mathrm{HCl}$ were now added and the mixture allowed to stand at room temperature for 24 hours. On back-titration $9 \cdot 48 \mathrm{ml}$. $N / 10 \mathrm{NaOH}$ were required. These figures show that reversion of the tribasic form to the dibasic form was complete and indicate the probable presence of a $\gamma$-lactone ring.

The above conclusions were confirmed by the preparation of the silver salts of the open and closed ring forms which were found to contain 47.80 and $39 \cdot 35 \% \mathrm{Ag}$ respectively. (Theoretical for $\mathrm{C}_{16} \mathrm{H}_{25} \mathrm{O}_{8} \mathrm{Ag}_{3}, 48 \cdot 39 \%$, and for $\mathrm{C}_{16} \mathrm{H}_{24} \mathrm{O}_{7} \mathrm{Ag}_{2}, 39 \cdot 67 \%$.)

It was found impossible to isolate the open ring form of minioluteic acid in the free state. A quantity of minioluteic acid was hydrolysed by heating with a measured excess of $\mathrm{N} \mathrm{NaOH}$. The cooled hydrolysate was shaken with ether and rather less than the theoretical amount of $N / 10 \mathrm{HCl}$ cautiously added with constant shaking, 1-2 ml. at a time. The ethereal solution was treated at room temperature with light petroleum and the material separating was air-dried. It showed an equivalent on titration of 169. (Theoretical for closed form 165, for open form 116.) In a further attempt to prepare the trimethyl ester of the open form of minioluteic acid the ethereal solution as obtained above was methylated directly with diazomethane. The resultant crystalline product proved to be the dimethyl ester, M.P. $86^{\circ}$ (see p. 832).

Rotations. (a) Free acid in acetone

$$
c=1 \cdot 07 .[\alpha]_{5461}^{16}+108 \cdot 1^{\circ},[\alpha]_{5790}^{16}+94 \cdot 5^{\circ} \text {. }
$$

(b) Disodium salt in water, calculated as the free acid.

$$
c=1 \cdot 04 .[\alpha]_{5461}^{19}+62 \cdot 4^{\circ},[\alpha]_{5790}^{19}+54 \cdot 6^{\circ} .
$$

Solubilities. Minioluteic acid is readily soluble in cold ether, ethyl alcohol, acetone, ethyl acetate, butyl alcohol and hot water. It is somewhat soluble in chloroform $(1: 400)$ and is practically insoluble in cold water, benzene and light petroleum. 
Salts. Minioluteic acid gives insoluble salts with a large number of metals and in this respect is very similar to spiculisporic acid. A $1 \%$ neutral solution of the sodium salt of minioluteic acid gave heavy precipitates with silver nitrate, ferric chloride, lead acetate and the chlorides of calcium, barium, nickel and zinc; moderate precipitates with copper sulphate and magnesium chloride, and no precipitate with mercuric chloride, uranium acetate and aqueous potassium chloride. In contrast with spiculisporic acid, minioluteic acid gives a potassium salt which is almost insoluble in alcohol, the potassium salt of spiculisporic acid being relatively soluble in this solvent.

Dimethyl ester. Minioluteic acid, dissolved in ether, was treated with an excess of an ethereal solution of diazomethane. Vigorous evolution of nitrogen took place and the ethereal solution was filtered, evaporated and the crystalline residue recrystallised from a mixture of chloroform and light petroleum. Colourless plates, M.P. $86.5^{\circ}$. (Found: $\mathrm{C}, 60 \cdot 61,60.58 ; \mathrm{H}, 8.44,8.22 ; \mathrm{OCH}_{3}, 17 \cdot 41$, $17 \cdot 64 \% . \mathrm{C}_{16} \mathrm{H}_{24} \mathrm{O}_{5}\left(\mathrm{OCH}_{3}\right)_{2}$ requires $\mathrm{C}, 60 \cdot 30 ; \mathrm{H}, 8 \cdot 44 ; \mathrm{OCH}_{3}, 17 \cdot 32 \%$.)

Trihydrazide. $0.08 \mathrm{~g}$. of the dimethyl ester of minioluteic acid was dissolved in 2-3 ml. ethyl alcohol and $0 \cdot 16 \mathrm{ml}$. of $50 \%$ aqueous hydrazine hydrate added. Deposition of micro-crystals began immediately. These were drained, washed with ethyl alcohol and dried in vacuo over $\mathrm{H}_{2} \mathrm{SO}_{4}$. As no suitable crystallising medium could be found the compound was analysed without recrystallisation. The crystals sintered with incipient decomposition at $157-160^{\circ}$ and melted finally at $201^{\circ}$. (Found: C, 49.37, 49.22; H, 8.72, 8.60; N, 21.30, 21.30\%. $\mathrm{C}_{16} \mathrm{H}_{34} \mathrm{O}_{5} \mathrm{~N}_{6}$ requires $\mathrm{C}, 49 \cdot 19 ; \mathrm{H}, 8 \cdot 78 ; \mathrm{N}, 21.52 \%$.)

A saturated aqueous solution of minioluteic acid does not reduce acid potassium permanganate in the cold although the permanganate is slowly reduced on heating. An alcoholic solution of the acid showed no absorption of hydrogen after 45 minutes' shaking with palladised norite. With Wijs's iodine solution 1 g.-mol. of minioluteic acid absorbed $0 \cdot 845$ g.-atom of iodine after 2 hours, but this is almost certainly due to chemical reactions other than the simple addition of iodine. These facts together with the analytical figures obtained for minioluteic acid and its dimethyl ester and trihydrazide indicate the absence from the molecule of the acid of an unsaturated linkage.

\section{Potash fusion of minioluteic acid.}

$1 \mathrm{~g}$. minioluteic acid was warmed with $5 \mathrm{~g}$. solid $\mathrm{KOH}$ and $3 \mathrm{ml}$. water in a nickel crucible. When dissolution was complete the temperature of the metalbath was raised slowly to $310^{\circ}$ and maintained at this temperature for one hour. The melt was dissolved in water and acidified with dilute $\mathrm{H}_{2} \mathrm{SO}_{4}$. There was a considerable evolution of $\mathrm{CO}_{2}$ and a slight smell of butyric acid. The mixture was kept in the cold room overnight and filtered from precipitated material, and the filtrate and precipitate were dealt with separately.

(a) Filtrate. The filtrate was exhaustively extracted with ether in a continuous extraction apparatus for 30 hours. On evaporation of the ether a crystalline residue, weight $0.41 \mathrm{~g}$., was obtained. This was dissolved in water, titrated with $N \mathrm{NaOH}$ (equivalent $=61$ ), the neutralised solution was acidified with acetic acid and the oxalic acid removed by precipitation with calcium chloride. Weight of calcium oxalate $=0.50 \mathrm{~g}$. The oxalic acid-free solution was now acidified with $\mathrm{H}_{2} \mathrm{SO}_{4}$ and re-extracted with ether. The ether solution on evaporation left only a trace of residue from which no succinic or other crystalline acid could be isolated.

(b) Precipitate. Weight $0 \cdot 48 \mathrm{~g}$. This was purified by crystallisation from a mixture of ether and chilled light petroleum giving a small quantity ( $0.06 \mathrm{~g}$.) 
of colourless, crystalline plates, M.P. $87-89^{\circ}$, which on recrystallisation from acetone and water melted at $90-91^{\circ}$ and had a barely detectable optical rotation. (Found: $\mathrm{C}, 65 \cdot 02,64 \cdot 85 ; \mathrm{H}, 9 \cdot 99,10 \cdot 12 \%$. Mol. wt., 246, 250. $\mathrm{C}_{14} \mathrm{H}_{26} \mathrm{O}_{4}$ requires: C, $65 \cdot 07 ; \mathrm{H}, 10 \cdot 16 \%$; mol. wt., 258.) Equivalent by titration 130. (Theoretical for $\mathrm{C}_{14} \mathrm{H}_{26} \mathrm{O}_{4}$ titrating as a dibasic acid, 129.1.) This acid was subsequently shown by synthesis to be decylsuccinic acid (II).

It was evident that a second acid was present in the precipitate $(b)$. Hence the combined precipitates $(b)$ from the potash fusion of $5 \mathrm{~g}$. minioluteic acid were distilled in vacuo at $16 \mathrm{~mm}$. with the following results:

Fraction $I$, collected up to $135^{\circ}$. Weight 0.45 g. Softens at $30^{\circ}$. M.P. $38-40^{\circ}$.

Fraction $I I$, collected from 135 to $145^{\circ}$. Weight $0.57 \mathrm{~g}$. Softens at $34^{\circ}$. M.P. $44-44 \cdot 5^{\circ}$.

Fraction III. B.P. gradually fell to $100^{\circ}$. Weight $0 \cdot 39 \mathrm{~g}$. Softens at $41^{\circ}$. M.P. $43-48 \cdot 5^{\circ}$.

Fraction $I V$. The residue in the distillation-flask was now distilled at $7 \mathrm{~mm}$. when a fourth fraction distilled at $182^{\circ}$. Weight $0 \cdot 74$ g. M.P. about $58^{\circ}$.

Fraction I was esterified with diazomethane in ether and the residue on evaporation of the ether was treated with $2.7 \mathrm{ml}$. ethyl alcohol and $1 \mathrm{ml} .50 \%$ aqueous hydrazine hydrate and allowed to stand for 24 hours. A total yield of $0: 32 \mathrm{~g}$. of hydrazide was obtained, which was crystallised twice from aqueous alcohol and once from benzene, M.P. $104-105^{\circ}$. A sample of $n$-dodecanoic acid hydrazide prepared similarly melted at $106-107^{\circ}$, and there was no depression in melting-point on mixing the two samples. (Found: $\mathrm{C}, 67 \cdot 25,67 \cdot 34 ; \mathrm{H}, 11 \cdot 82$, $11.98 ; \mathrm{N}, 13.41,13.25 \%$. $n$-Dodecanoic acid hydrazide, $\mathrm{C}_{12} \mathrm{H}_{26} \mathrm{ON}_{2}$ requires: C, $67 \cdot 23 ; \mathrm{H}, 12 \cdot 24 ; \mathrm{N}, 13 \cdot 07 \%$.)

Fraction IV, distilling at $182^{\circ} / 7 \mathrm{~mm}$., was recrystallised several times from ether-light petroleum giving finally colourless needles, which after sublimation had M.P. $66-67^{\circ}$. This was shown to be the anhydride of decylsuccinic acid (see below).

\section{Synthesis of decylsuccinic acid (II).}

The method adopted was to condense ethyl- $\alpha$-bromo- $n$-dodecanoate with ethyl sodiomalonate, and then to decarboxylate the tricarboxylic acid obtained on hydrolysis.

$\alpha$-Bromo-n-dodecyl bromide and ethyl $\alpha$-bromo-n-dodecanoate. $\alpha$-Bromo- $n$-dodecyl bromide was synthesised by the method of Auwers and Bernhardi [1891]. $n$-Dodecanoic acid (10 g.) and red phosphorus $(0.52 \mathrm{~g}$.) were placed in a flask fitted with a reflux condenser and bromine $(14 \cdot 7 \mathrm{~g})$. added slowly. The temperature was slowly raised to $90-100^{\circ}$. A little more bromine was added at intervals until the evolution of $\mathrm{HBr}$ ceased. The mixture was cooled and the crude product converted, without previous isolation, into ethyl $\alpha$-bromo- $n$-dodecanoate by the addition of ethyl alcohol $(30 \mathrm{ml}$.). The mixture was kept for some hours, the excess of alcohol removed in vacuo, the residue dissolved in ether, washed with water and aqueous sodium carbonate solution, dried over anhydrous $\mathrm{Na}_{2} \mathrm{SO}_{4}$ and distilled in vacuo. The main fraction (13.7 g.) distilled at $115-123^{\circ} / 1 \mathrm{~mm}$.

Triethyl $\alpha \beta$-dicarboxytridecanoate. Sodium (0.88 g.) was dissolved in ethyl alcohol (12 ml.) and ethyl malonate (6.1 g.) added. After half an hour ethyl $\alpha$-bromo- $n$-dodecanoate ( $11 \cdot 7$ g.) was added and the mixture heated for 2 hours on the water-bath under reflux. Excess ethyl alcohol was removed by vacuum evaporation, water was added to dissolve the sodium bromide and the mixture was extracted with ether, the extract being dried with $\mathrm{Na}_{2} \mathrm{SO}_{4}$ and fractionated in vacuo. The main fraction (11.5 g.) distilled at $172^{\circ} / 1 \mathrm{~mm}$.

$\alpha \beta$-Dicarboxytridecanoic acid. It was found that the triethyl ester was difficult to hydrolyse completely with alcoholic potash, but satisfactory results were obtained by fusion with potash. The ester was heated with five times its weight of stick potash and three times its weight of water, the temperature of the bath being raised as rapidly as frothing would permit to $300^{\circ}$. The melt was cooled, dissolved in water, acidified, and the beautifully crystalline product filtered off 
(M.P. $148^{\circ}$, decomp.). It was recrystallised from a mixture of ether and four volumes of light petroleum. Colourless needles, M.P. $148^{\circ}$ (decomp.). (Found: C, 59.27, 59.37; H, 8.56, 8.60\% $\mathrm{C}_{15} \mathrm{H}_{26} \mathrm{O}_{6}$ requires: $\mathrm{C}, 59 \cdot 57 ; \mathrm{H}, 8.67 \%$. Equivalent by titration, $100 \cdot 4$. Theoretical for $\mathrm{C}_{15} \mathrm{H}_{26} \mathrm{O}_{6}$ titrating as a tribasic acid, 100-7.)

Decylsuccinic anhydride. $\alpha \beta$-Dicarboxytridecanoic acid was decarboxylated by distillation in vacuo. The product distilled at $160^{\circ} / 2 \mathrm{~mm}$. and solidified in the receiver. It separated from light petroleum in colourless plates, M.P. $65-66^{\circ}$; after sublimation $68 \cdot 5^{\circ}$. When mixed with the anhydride, M.P. 66-67 $7^{\circ}$ obtained from minioluteic acid (Fraction IV, p. 833) it showed no depression in melting-point. (Found: $\mathrm{C}, 69.90 ; \mathrm{H}, 9 \cdot 88 \% \cdot \mathrm{C}_{14} \mathrm{H}_{24} \mathrm{O}_{3}$ requires : C, 69.93; H, $10 \cdot 07 \%$.)

Decylsuccinic acid. Decylsuccinic anhydride $(0.50 \mathrm{~g}$.) was heated with $10 \mathrm{ml}$. $\mathrm{N} \mathrm{NaOH}$ for half an hour on the water-bath. A back-titration with $N \mathrm{HCl}$ gave an apparent equivalent of 116 (theoretical 120). Sufficient excess of $\mathrm{HCl}$ was added to precipitate all the acid. The precipitate $(0.5$ g.) was recrystallised first from light petroleum and then from aqueous acetone, forming colourless glistening plates, M.P. 90-91 . This melting-point showed no depression on mixing with the dibasic acid, M.P. $90-91^{\circ}$, obtained by potash fusion of minioluteic acid (see p. 833).

\section{Reduction of minioluteic acid with sodium amalgam.}

Minioluteic acid (2 g.) was dissolved in $2 \mathrm{~N} \mathrm{NaOH} \mathrm{(25} \mathrm{ml.)} \mathrm{and} \mathrm{water} \mathrm{(75} \mathrm{ml.)}$ added. Sodium amalgam (100 g., $2.5 \%$ sodium) was added and the mixture heated on the water-bath. After 4 hours a further $100 \mathrm{~g}$. sodium amalgam were added and so on until a total of $500 \mathrm{~g}$. had been added. From time to time a little concentrated $\mathrm{HCl}$ was added to reduce the alkalinity, but the solution was never allowed to become acid. Finally, the mixture was cooled, acidified with $\mathrm{HCl}$, extracted with ether and the ether removed, giving a residue, weight $1 \cdot 37 \mathrm{~g}$. The residue appeared to be a mixture of substances and was ground and extracted in a Soxhlet with light petroleum, B.P. $60-80^{\circ}$, giving $0 \cdot 1 \mathrm{~g}$. of a colourless crystalline product, M.P. $114^{\circ}$. The sticky residue which was now difficult to extract was dissolved in absolute alcohol and treated with an alcoholic solution of potassium acetate, giving a precipitate from which no crystalline material could be separated. The alcoholic solution was evaporated in vacuo and extracted with cold water. The insoluble portion was dissolved in hot water and acidified. The resultant precipitate, weight $0 \cdot 16$ g., M.P. $113^{\circ}$, was identical with the acid previously extracted with light petroleum, M.P. $114^{\circ}$. The combined fractions were recrystallised from ether-light petroleum giving colourless plates, M.P. $114 \cdot 5^{\circ}$, which, after sublimation in a high vacuum, was raised to $119^{\circ}$. (Found: $\mathrm{C}, 66 \cdot 82,66.92 ; \mathrm{H}, 9 \cdot 37,9 \cdot 32 \% \cdot \mathrm{C}_{15} \mathrm{H}_{26} \mathrm{O}_{4}$ requires: $\mathrm{C}, 66.61 ; \mathrm{H}, 9 \cdot 70 \%$.)

$0.0856 \mathrm{~g}$. required $3 \cdot 15 \mathrm{ml} . \mathrm{N} / 10 \mathrm{NaOH}$ for neutralisation in the cold, and on heating with excess $N / 10 \mathrm{NaOH}$ required a further $3.37 \mathrm{ml}$. corresponding to equivalents of 272 and 131. $\mathrm{C}_{15} \mathrm{H}_{26} \mathrm{O}_{4}$ titrating as a mono- or di-basic acid requires 270 or 135 respectively.

This reduction product, $\mathrm{C}_{15} \mathrm{H}_{26} \mathrm{O}_{4}$, which is obviously the monolactone of a dibasic acid, thus differs from minioluteic acid, $\mathrm{C}_{16} \mathrm{H}_{26} \mathrm{O}_{7}$, by one atom of oxygen and one molecule of $\mathrm{CO}_{2}$. It has been shown by synthesis to be the $\gamma$-lactone of $\alpha$-hydroxy- $\gamma$-carboxy- $n$-tetradecanoic acid (III).

\section{Synthesis of the $\gamma$-lactone of $\alpha$-hydroxy- $\gamma$-carboxy-n-tetradecanoic acid (III).}

Ethyl decylsuccinate was condensed with ethyl oxalate in the presence of sodium ethoxide in ether, according to the method of Blaise and Gault [1911]. The resulting condensation product was hydrolysed and decarboxylatedin alkaline solution and subsequently reduced with sodium amalgam.

Diethyl decylsuccinate. Decylsuccinic acid (16 g.) was esterified in the usual manner with two successive amounts of absolute ethyl alcohol (100 ml.) containing $3 \%$ of $\mathrm{HCl}$. The resultant ester was distilled in vacuo, B.P. $155-159^{\circ} / 2 \mathrm{~mm}$., weight $15 \cdot 9 \mathrm{~g}$. 
$\alpha-K e t o-\gamma$-carboxy-n-tetradecanoic acid. Powdered metallic sodium (1-15 g.) was treated with ethyl alcohol $(2 \cdot 3 \mathrm{~g}$.) diluted with $20-30 \mathrm{ml}$. of ether. The mixture was allowed to stand overnight and ethyl oxalate $(7 \cdot 3 \mathrm{~g}$.) added. After 2 hours ethyl decylsuccinate $(15 \cdot 7 \mathrm{~g}$.$) was added and$ the mixture left at room temperature for 48 hours. The mixture was poured into $20 \mathrm{ml}$. of $20 \%$ $\mathrm{H}_{2} \mathrm{SO}_{4}$ and $25 \mathrm{~g}$. of ice, shaken and the ether layer separated. In the method described by Blaise and Gault [1911] for the preparation of $\alpha$-keto- $\gamma$-methylglutaric acid, on which this method is based, the corresponding triethyl ester was extracted from the ether solution at this stage by means of aqueous $(25 \%$ ) potassium carbonate. A similar procedure in our hands failed to extract any triethyl $\alpha$-keto- $\beta \gamma$-dicarboxy- $n$-tetradecanoate, probably owing to the feebler acidity of our ester. The ether solution was therefore extracted with $N \mathrm{NaOH}$. By this means $6 \cdot 7 \mathrm{~g}$. of material were extracted whilst $11.7 \mathrm{~g}$. of presumably uncondensed esters remained in the ether. The $\mathrm{NaOH}$ solution was now heated at $100^{\circ}$ for 14 hours, cooled, acidified and extracted with ether. The ether solution was evaporated, giving a semicrystalline residue (4.2 g.), from which the liquid portion and a quantity of decylsuccinic acid were separated by fractionation from ether-light petroleum. The remainder (1.2 g.) consisted of impure $\alpha$-keto- $\gamma$-carboxy- $n$-tetradecanoic acid. A pure sample of this acid was not prepared, but it was characterised by the preparation of its 2:4-dinitrophenylhydrazone.

2:4-Dinitrophenylhydrazone of $\alpha$-keto- $\gamma$-carboxy-n-tetradecanoic acid. This was prepared by Brady's method [1931] from the crude product referred to above and was recrystallised from $70 \%$ aqueous ethyl alcohol. Yellow needles, M.P. $180^{\circ}$. (Found on material dried to constant weight at $100^{\circ}: \mathrm{C}, 54 \cdot 40 ; \mathrm{H}, 6 \cdot 62 ; \mathrm{N}, 11 \cdot 90 \% \cdot \mathrm{C}_{21} \mathrm{H}_{30} \mathrm{O}_{8} \mathrm{~N}_{4}$ requires: $\mathrm{C}, 54 \cdot 05 ; \mathrm{H}, 6 \cdot 49 ; \mathrm{N}, 12 \cdot 01 \%$.)

$\gamma$-Lactone of $\alpha$-hydroxy- $\gamma$-carboxy-n-tetradecanoic acid $(I I I)$. The crude acid ( $0.7 \mathrm{~g}$.$) was re-$ duced in alkaline solution with sodium amalgam (400 g., $2.5 \%$ sodium) over a period of 16 hours on a boiling water-bath. The method used was similar to that followed for the hydrolysis and reduction of minioluteic acid. The resultant product was purified by fractionation from etherlight petroleum. Colourless plates. Weight $0 \cdot 3$ g. M.P. $119^{\circ}$, alone or in admixture with the lactone obtained by hydrolysis and reduction of minioluteic acid (p. 834). (Found: C, 66.37; $\mathrm{H}, 9 \cdot 66 \% \cdot \mathrm{C}_{15} \mathrm{H}_{26} \mathrm{O}_{4}$ requires: $\mathrm{C}, 66 \cdot 61 ; \mathrm{H}, 9 \cdot 70 \%$.)

\section{SUMMARY AND DISCUSSION.}

The metabolic products of $P$. minio-luteum Dierckx, when grown at $24^{\circ}$ on Czapek-Dox medium containing glucose as the sole source of carbon, have been investigated. Two aliphatic acids of complex structure have been isolated: $(a)$ the $\gamma$-lactone of $\gamma$-hydroxy- $\beta \delta$-dicarboxypentadecanoic acid (I) previously described by Clutterbuck et al. [1931] as a metabolic product of $P$. spiculisporum Lehman, for which the name spiculisporic acid is now proposed, and $(b)$ a hitherto undescribed acid for which the name minioluteic acid is proposed.

The evidence for the molecular constitution of minioluteic acid is briefly as follows :

(1) Minioluteic acid has the empirical formula $\mathrm{C}_{16} \mathrm{H}_{26} \mathrm{O}_{7}$. It is a saturated dextrorotatory acid and titrates in the cold as a dibasic, and on heating as a tribasic acid. Because of the stability of the lactone ring the latter is probably of the $\gamma$-type.

(2) It gives a dimethyl ester and a trihydrazide.

(3) On fusion with potash, oxalic acid, $n$-dodecanoic acid, and decylsuccinic acid (II) $\mathrm{C}_{14} \mathrm{H}_{26} \mathrm{O}_{4}$ but no succinic acid were isolated. Decylsuccinic acid has been synthesised.

(4) On reduction with sodium amalgam minioluteic acid gives the $\gamma$-lactone of $\alpha$-hydroxy- $\gamma$-carboxy- $n$-tetradecanoic acid $\mathrm{C}_{15} \mathrm{H}_{26} \mathrm{O}_{4}$ (III), the constitution of which has been settled by synthesis. This change involves the loss of a molecule of $\mathrm{CO}_{2}$ and an atom of oxygen. The above facts are easily interpreted by assigning to minioluteic acid the molecular constitution (IV), i.e. the $\gamma$-lactone of $\alpha \beta$-dihydroxy- $\beta \gamma$-dicarboxy- $n$-tetradecanoic acid. 
The origin of the products given on potash fusion and on reduction with sodium amalgam may be readily explained by postulating the formation of an intermediate product $\alpha$-keto- $\beta \gamma$-dicarboxy- $n$-tetradecanoic acid (V) (or its corresponding enol form) from minioluteic acid in alkaline solution by loss of a molecule of water. The conversion in aqueous solution of $\alpha \beta$-dihydroxy-compounds, particularly of aliphatic nature, into the corresponding aldehyde or ketone by loss of a molecule of water is a well-known reaction [Lieben, 1902].

If the intermediate formation of $\alpha$-keto- $\beta \gamma$-dicarboxy- $n$-tetradecanoic acid (V) be accepted the origin of the products isolated becomes obvious. Since the keto-group in this compound is in the $\beta$-position with regard to the $\beta$-carboxygroup this substance should behave as a $\beta$-keto-acid. By analogy with acetoacetic acid, which on hydrolysis with strong potash gives rise to two molecules of acetic acid, $\alpha$-keto- $\beta \gamma$-dicarboxy- $n$-tetradecanoic acid $(\mathrm{V})$ under similar conditions (i.e. potash fusion) should yield oxalic and decylsuccinic acids. The latter may be presumed to break down further in presence of oxygen and afford. $n$-dodecanoic and oxalic acids in the same way as succinic acid, which under these conditions gives oxalic acid. This accounts for all the degradation products isolated after subjecting minioluteic acid to potash fusion.

On hydrolysis with dilute alkali $\alpha$-keto- $\beta \gamma$-dicarboxy- $n$-tetradecanoic acid (V) would be expected to give rise to $\alpha$-keto- $\gamma$-carboxy- $n$-tetradecanoic acid and $\mathrm{CO}_{2}$, by elimination of the $\beta$-carboxy-group, just as acetoacetic acid under these conditions affords acetone and $\mathrm{CO}_{2}$. Reduction with sodium amalgam would then convert the keto-group into a hydroxy-group, the final product being $\alpha$-hydroxy- $\gamma$-carboxy- $n$-tetradecanoic acid (III). This hypothesis is confirmed by the method used for synthesis of $\alpha$-hydroxy- $\gamma$-carboxy- $n$-tetradecanoic acid since the decarboxylation and subsequent reduction of $\alpha$-keto- $\beta \gamma$-dicarboxy$n$-tetradecanoic acid, which must here be the first product of synthesis, follows the same course. The two typical methods of breakdown of a $\beta$-keto-acid are thus represented.

A comparison of the constitutional formulae assigned to spiculisporic and minioluteic acids reveals the fact that both are mono- $\gamma$-lactones of tricarboxylic acids. Considering for simplicity the hydrolysed, non-lactonic forms, it is seen that both contain the $n$-dodecanoic acid grouping, but whereas in spiculisporic acid this is linked by the $\alpha$-carbon through a carbinol group with succinic acid, in minioluteic acid it is linked, again by the $\alpha$-carbon, to dihydroxysuccinic (i.e. tartaric) acid, but without the intervention of a carbinol group.

This work has been rendered possible by a grant to one of us (J. H. B.) from the Research Council of Imperial Chemical Industries Ltd., to whom we tender our best thanks.

\section{REFERENCES.}

Auwers and Bernhardi (1891). Ber. deutsch. chem. Ges. 24, 2224.

Biourge (1923). La Cellule, 33, 237.

Blaise and Gault (1911). Bull. Soc. Chim. (4), 9, 458.

Brady (1931). J. Chem. Soc. 756.

Clutterbuck, Raistrick and Rintoul (1931). Phil. Trans. Roy. Soc. Lond. B 220, 301.

Dierckx (1901). Ann. Soc. Sci. Bruxelles, 25, 83.

Lieben (1902). Monatsh. Chem. 23, 60.

Thom (1930). The Penicillia, 464. (London: Baillière, Tindall and Cox.) 